\title{
Enhancement Of Cocoa Quality By The Indigenous Yeast Candida Tropicalis KLK4 Through Cocoa Bean Fermentation
}

\author{
Jamili1 ${ }^{1}$, Nur Arfa Yanti ${ }^{1}$, Prima Endang Susilowati ${ }^{2}$ \\ Biologi Department, Faculty of Mathematics and Natural Science Halu Oleo University, \\ Kendari Southeast Sulawesi, Indonesia. \\ jamili66@yahoo.com \\ Department, Faculty of Mathematics and Natural Science Halu Oleo University,
}

Kendari Southeast Sulawesi, Indonesia.

arfayanti73@yahoo.com

Chemistry Department, Faculty of Mathematics and Natural Science Halu Oleo University, Kendari Southeast

Sulawesi, Indonesia.

primachem_kdi@yahoo.com

"Correspondence address:

Nur Arfa Yanti

Microbiology Laboratory, Biology department Halu Oleo University, Kendari.

E-mail : arfayanti73@yahoo.com

\section{ABSTRACT}

An indigenous yeast strain that isolated from fermented cocoa bean has a role in cocoa bean fermentation process, was characterized and identified to be member of the Candida tropicalis species based on phenotypic characteristics and the D1/D2 region of the large subunit rRNA gene. Properties of importance for cocoa bean fermentation, namely sucrose, glucose, and citrate assimilation capacity, $\mathrm{pH}-$, ethanol-, and heat-tolerance, were examined for isolate. The Quality of fermented cocoa bean was analyzed by cut test. Candida tropicalis KLK4 was tolerance to low pH value, high temperature, ethanol and could assimilate citrate, reflecting it is able to adapt to cocoa fermentation environment. The utilization of Candida tropicalis KLK4 strain as a starter culture for cocoa fermentation can enhance cocoa quality.

\section{Indexing terms/Keywords}

Indigenous yeast, Candida tropicalis; Cocoa quality, Cocoa bean, Fermentation.

\section{Academic Discipline and Sub-Disciplines}

Microbiology.

\section{Subject Classification}

Biology.

Type (Method/Approach)

Quasi-Experimental.

\section{Council for Innovative Research}

Peer Review Research Publishing System

Journal: JOURNAL OF ADVANCES IN BIOTECHNOLOGY

Vol .4, No. 1.

www.ciribt.org ,jbteditor@gmail.com 


\section{INTRODUCTION}

The fermentation step plays an important role for the final quality of the cocoa beans. Fermentation helps to break down the mucilaginous pulp surrounding beans and causes cotyledon death [15]. It also helps to trigger biochemical changes inside the beans that contribute to reducing bitterness and astringency, and to the development of flavour precursors [15].

Three kinds of microbial groups, namely yeasts, lactic acid bacteria and acetic acid bacteria are involved in the fermentation process. Yeast serve several functions during cocoa bean fermentation [18]. Their main activity is metabolism of pulp sugars to produce ethanol, and an array of secondary metabolites. Yeasts proliferate in the early stages and decline upon prolonged fermentation due to exhaustion of appropriate energy sources, production of ethanol and its conversion to acetic acid, and a temperature increase of up to $50^{\circ} \mathrm{C}$ due to aerobic oxidation reactions [6,19]. At the same time, polysaccharides in the cells of the mucilaginous tissue are broken down by the pectinolytic action of yeast [18]. Some yeast utilise the citric acid of the pulp, and this contributes to the equilibration of cotyledon $\mathrm{pH}$, which impacts on endogenous enzyme activity [9].

Several yeasts have been reported to be associated with fermenting cocoa. In a recent study by Ardhana and Fleet [3] in East Java, Indonesia, amongst others Kloeckera apis, Saccharomyces cerevisiae and Candida tropicalis were found to be the most significant yeast species. However, it is not enough information about the role of yeasts on cocoa bean fermentation process. To better understand how individual species contribute to cocoa bean fermentation and its quality, the study of controlled fermentation that integrate physchochemical analyzes is required. The objective of this paper is to identify the indigenous yeast from Southeast Sulawesi, Indonesia and to determine contribution of the indigenous yeast on cocoa bean quality.

\section{MATERIALS AND METHODS}

\section{Microorganisms}

The yeast strain was isolated from fermented cocoa bean that retrieved from Kolaka regency, Southeast Sulawesi, Indonesia. The culture was kept in Potato Dextrose Agar (PDA) at $4^{\circ} \mathrm{C}$. The yeast starter for cocoa bean fermentation was grown in Potato Dextrose Broth medium containing $2 \%$ pulp.

\section{Identification of Yeast Strain}

The KLK4 strain was identified based on phenotypic and genotypic characterization. Phenotypic characterization was performed by examining morphological (colony colour, cell shape, cell division, asexual and sexual spore) and physiological properties (carbohydrate assimilation, sucrose fermentation, nitrate reduction, urea hydrolysis and growth at $39^{\circ} \mathrm{C}$ ). Morphological and physiological properties was done based on standard taxonomic criteria [12].

Identification of KLK4 strain based on genotypic characterization was conducted by D1/D2 region of 26S rRNA sequence comparison. Extraction of the genomic DNA from the strain yeast was accomplished using an illustra Nucleon Phytopure Genomic DNA Extraction Kits (RPN 8510/8511) (GE Health care UK Limited). The D1/D2 region of 26S rRNA was amplified by PCR using NL 1 (5'-CATATCAATAAGCGGAGGAAAAG-3') and NL 4

GTCCGTGTTTCAAGACGG-3') as the forward and reverse primers, respectively. Amplification reactions were performed

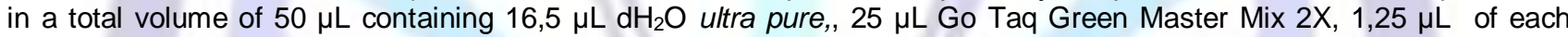
primer at $10 \mu \mathrm{M}, 1 \mu \mathrm{L}$ DMSO, $5 \mu \mathrm{L}$ template dsDNA (10-100 ng). PCR was performed using a TaKaRa Ex Taq Hot Start Version (TAKARA BIO, no. R007A) with initial denaturation stage of $5 \mathrm{~min}$ at $95^{\circ} \mathrm{C}$, followed by 30 cycles of denaturation for $30 \mathrm{sec}$ at $95^{\circ} \mathrm{C}$, annealing for $1 \mathrm{~min}$ at $52^{\circ} \mathrm{C}$, extension for $1 \mathrm{~min}$ at $72^{\circ} \mathrm{C}$ and a final extension at $72^{\circ} \mathrm{C}$ for $5 \mathrm{~min}$. Amplification products were analyzed by gel electrophoresis on $1 \%$ agarose gel using a $1 \mathrm{~kb}$ DNA ladder as a marker. PEG method was used for purification of the amplified PCR products and DNA strand of the amplified DNA fragment was then sequenced with the same PCR primers. Sequences of the amplified gene for each isolated yeast were merged in a single nucleotide alignment.

The D1/D2 region of the 26S rRNA gene sequence of KLK4 strain was aligned with representative ssequences retrieved from in the NCBI nucleotide sequence database (http://www.ncbi.nlm.nih.gov) and was edited manually. Pairwise evolutionary similarities and distances were computed by using the DNADIST program in the phylogeny inference package (PHYLIP) versi on 3,5. The phylogenetic tree was constructed by using the Neighbour-joining algorithm [17].

\section{Cocoa Fermentation-Related Physiological Characterization of Yeast Isolate}

Cocoa fermentation-related physiological characterization of yeast isolate was done to investigate adaptation ability of the yeast isolate to the cocoa bean fermentation environment. The following physiological characteristics of yeast isolate was determined in duplicate on a 10-mL scale in glass tubes : carbohydrate and citrate assimilation capacity, $\mathrm{pH}-$, ethanol-, and heat-tolerance. The test medium used was composed of $6.2 \mathrm{~g} / \mathrm{L}$ of yeast nitrogen base (YNB, Difco, Basingstoke, UK) and $5 \mathrm{~g} / \mathrm{L}$ of carbohydrate (glucose and sucrose) and citrate. YNB without added carbon source was used as a negative control. To test $\mathrm{pH}$ tolerance, YNB medium with glucose was adjusted to $\mathrm{pH} \mathrm{3,4}$ and 5.0 with $1 \mathrm{M} \mathrm{HCl}$. To test ethanol tolerance, YNB medium with glucose was supplemented with $5 \%, 10 \%$, or $15 \%(\mathrm{v} / \mathrm{v})$ ethanol. To test heat tolerance, YNB medium with glucose, adjusted to $\mathrm{pH} 5.5$, was incubated at 25,37 and $45^{\circ} \mathrm{C}$. All tubes were inoculated with $1 \%(\mathrm{v} / \mathrm{v})$ of a yeast culture grown at $30^{\circ} \mathrm{C}$ for $24 \mathrm{~h}$. Growth was determined by measurements of OD $600 \mathrm{~nm}$. 


\section{Micro Fermentation of Cocoa Beans}

Laboratory scale cocoa fermentation trials were carried out with $350 \mathrm{~g}$ of fresh cocoa beans (Forastero variety). The cocoa pods were retrieved from cocoa farm in Kolaka regency, Southeast Sulawesi, Indonesia. Ripe cocoa pods were first washed with detergent, dipped in phenol and finally sprayed with $5 \%$ thymol prepared in ethanol in a sterilized inoculation chamber to ensure aseptic conditions. The pods, together with all materials for the micro fermentation, were subjected to a final sterilization by u.v irradiation overnight [5]. The cocoa beans were collected in plastic box fermentation. Fermentation was carried out at room temperature for 5 days. The yeast strain was inoculated on the cocoa beans at $10^{6} \mathrm{CFU} / \mathrm{g}$ of cocoa beans. For comparison, fermentation of beans without inoculums addition (naturally fermentation) was also performed. Subsamples of about $100 \mathrm{~g}$ of fermented cocoa beans were taken at the end of different durations of fermentation process: 0,3 and 5 days. After fermentation, the fermented cocoa beans were dried in sunshine by exposition the beans on plastic and clean surface from 8 am to $5 \mathrm{pm}$ daily until the moisture content reached $7 \%-8 \%$ as commonly recommended in international cocoa standards (Wood \& Lass, 1985). Each samples were used for determination of physical quality of beans and fat content.

\section{Physical Quality Assessment of Fermented Cocoa Beans}

The cut test is used for evaluation of sanitary and fermentation quality of beans. A total of ninety $(3 \times 30)$ dried cocoa beans from each treatment were analyzed by the cut-test according to methods previously used by $[8,20]$. The beans were cut lengthwise through the middle using a penknife to expose the maximum cut surface of the cotyledons. Both halves of each bean were examined in full daylight according to the cross sectional color of the beans. Observations were made and beans were placed in one of the following categories: fully brown (fermented); purple (partly or under-fermented); slaty (unfermented); insect damaged; moldy; or germinated. Slaty beans include rubbery cotyledon, blackish color, and resistance to cutting. Defectives beans are the sum of germinated beans, insect infested beans and flat beans. Results were expressed as a percentage and according to the official standard, a batch of cocoa beans with more than $60 \%$ fully brown color beans is considered as good quality product. The fat content was measured using soxhlet extraction method [4].

\section{RESULTS}

\section{Identification of Yeast Strain}

KLK4 strain was an indigenous yeast that isolated from spontaneous cocoa bean fermentation was carried out at farm in Kolaka regency, Southeast Sulawesi, Indonesia. Identification of the yeast species (KLK4 strain) was done based on phenotypic and genotypic characterization. The phenotypic properties of KLK4 strain is summarized in Table 1. Cell characteristics of the KLK4 yeast strain was displayed in figure 1.

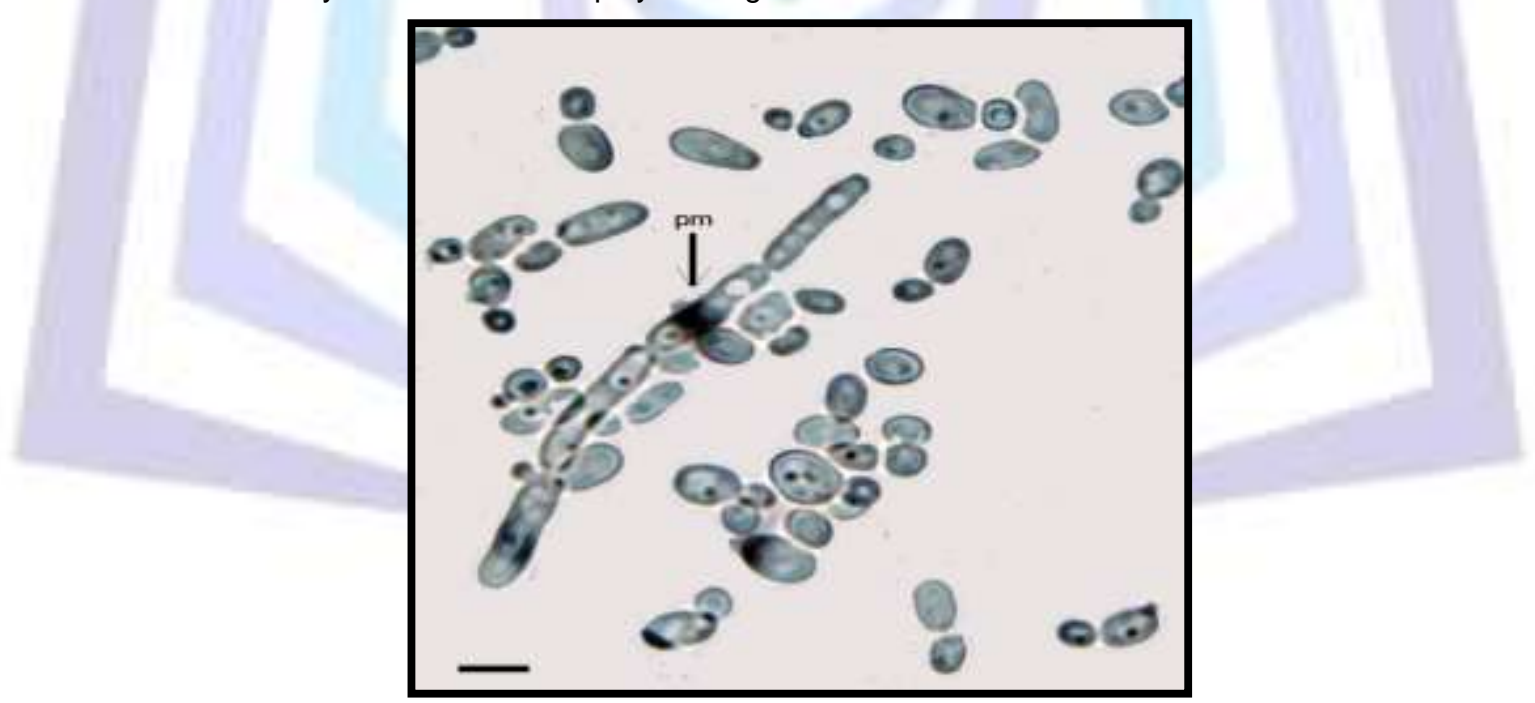

Figure 1. Microscopic features of indigenous yeast Candida tropicalis $\mathrm{KLK} 4$ (scale bars $=5 \mu \mathrm{m}$; pm =pseudomycelium).

Morphological characteristics of the KLK4 strain revealed that ellipsoidal and formed pseudomycelium (Fig. 1). The vegetative growth of KLK4 strain is multipolar budding.

Table 1 showed that the colonies KLK4 strain on Potato Dextrose Agar (PDA) is round, convex, opaque and cream colored. Chlamydospores are not produced and ascospores are not detected. The KLK4 strain assimilated of maltose but did not assimilate lactose and nitrate. The fermentation of glucose, sucrose and maltose is positive but lactose is negative. The KLK4 strain unable to hydrolyze urea, tolerance with ethanol and grew $39^{\circ} \mathrm{C}$. These characters were matched with key characters for Candida tropicalis (Kirsop et al., 1984). Hence, the KLK4 strain was identified as a member of species Candida tropicalis based on phenotypic characteristics. Result of identification based on phenotypic characteristics were used for an independent validation of the sequence-based identification. 
Table 1. Characteristics of yeast strain recovered from fermented cocoa bean

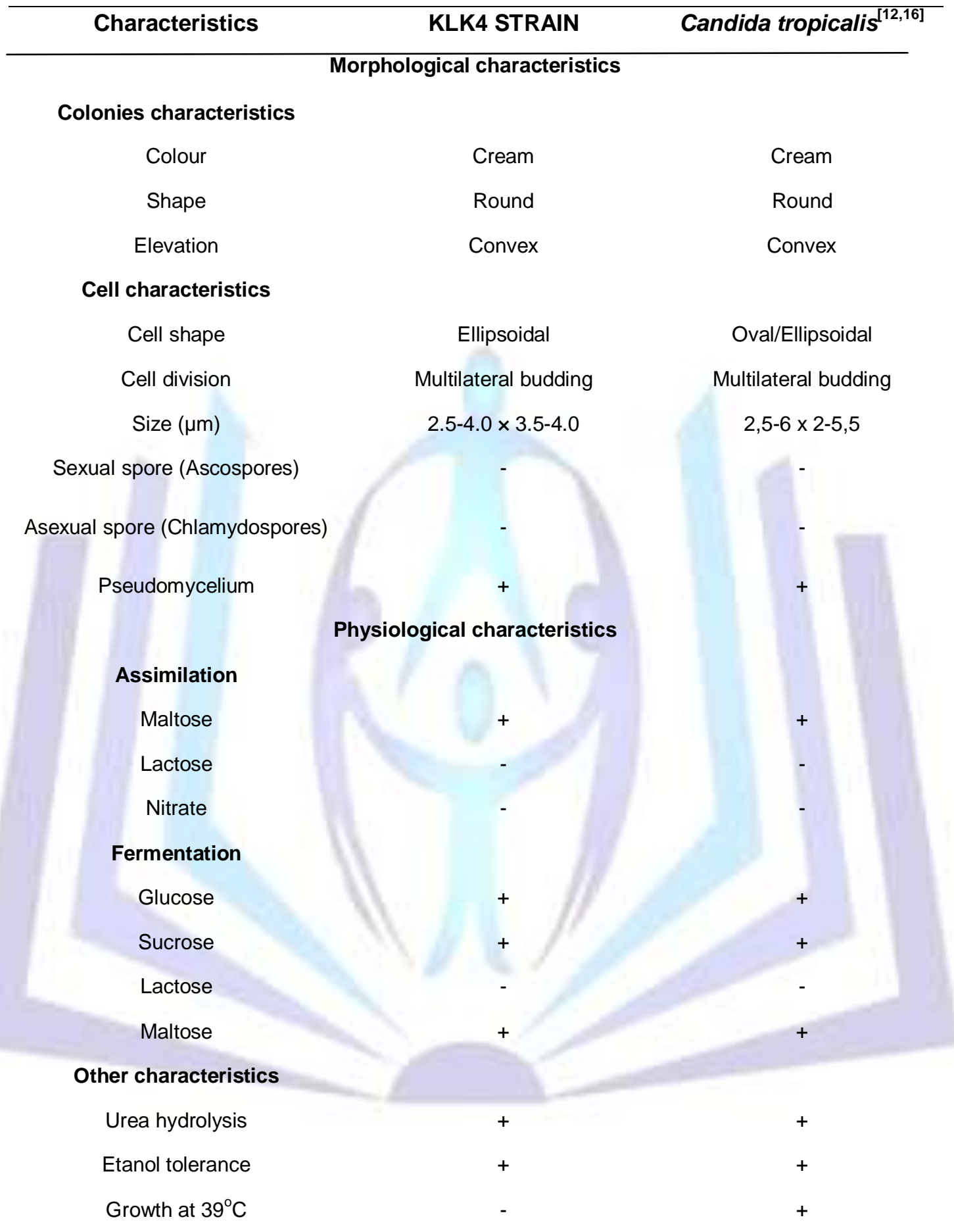

+ : positive reaction or growth, - : negative reaction or no growth observed

Identification of yeast strain KLK4 based on phylogenetic used sequence of the D1/D2 LSU. The phylogenetic analysis by Neighbour Joining method clearly placed isolate KLK4 to the Candida tropicalis clade (Figure 2). The analysis also showed further that, the closest relative of isolate KLK4 was Candida tropicalis XJURML (GenBank accession no. EF151501) (Figure 2). The isolate KLK4 has sequence similarity 99,83\% and showing 1 nucleotide differences from 583 base pairs of sequence in comparison with the reference strain of C.tropicalis XJURML (EF 151501). 


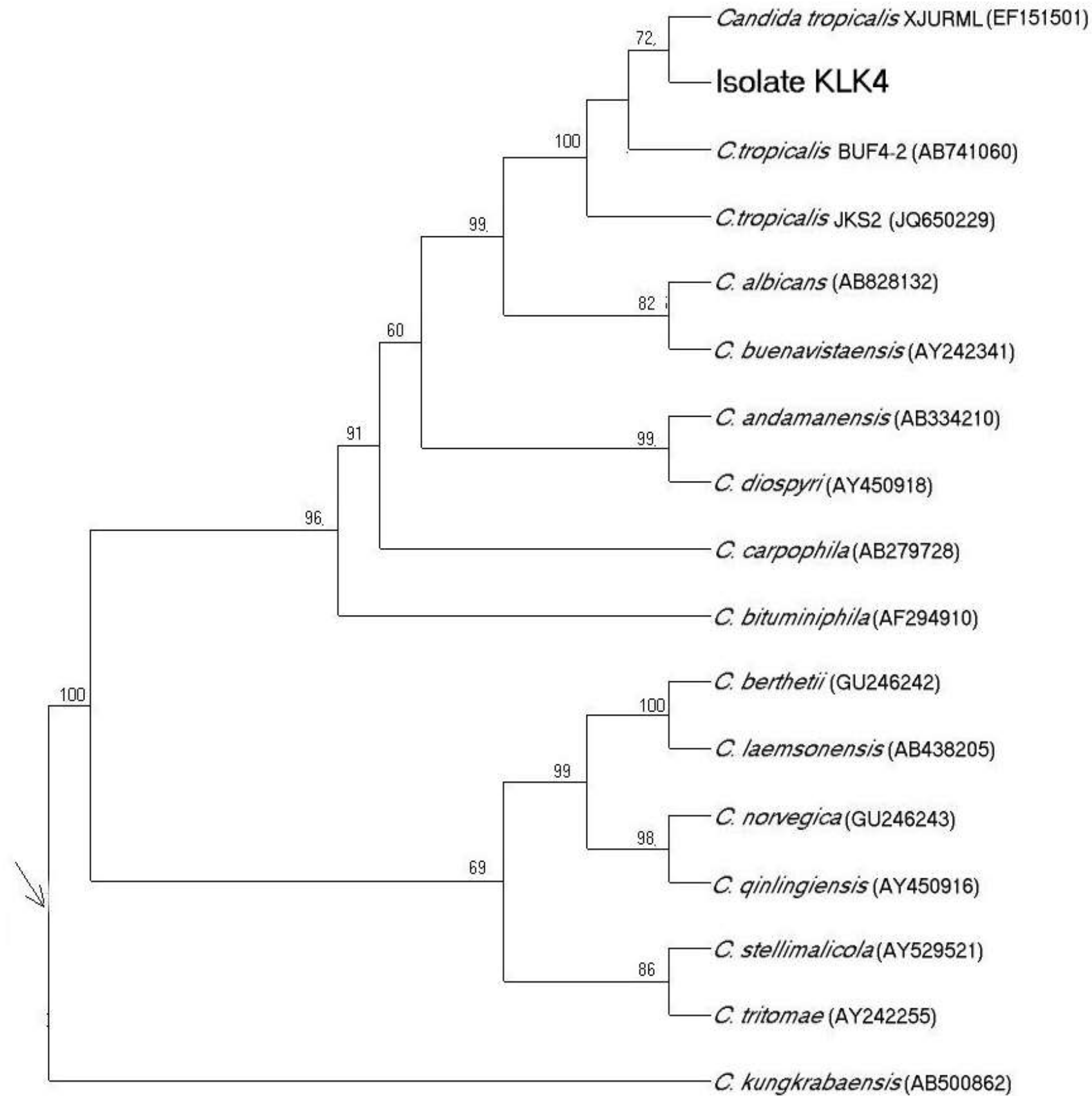

0,1

Figure 2. Phylogenetic tree showing relationships between yeast strain KLK4 and representatives of the genus Candida based on the D1/D2 region of the 26S rRNA gene sequences. The scale bar indicates 10 nucleotide substitution per 100 nucleotides in the D1/D2 region of the 26S rRNA gene sequences. The numbers at nodes indicate the levels of bootstrap support (\%) based on a neighbor-joining analysis of 1000 resampled data sets. The arrow indicates the estimated root position of the tree.

\section{Cocoa Fermentation-Related Physiological Characterization}

Characteristics of cocoa fermentation-related physiological of KLK4 strain is shown in Table 2. The physiological characteristics of the KLK4 strain that are important for the fermentation of cocoa. The KLK4 strain assimilated glucose, sucrose and citrate. The yeast strain grew at $\mathrm{pH} 3$ to 5 and grew at 25 to $40^{\circ} \mathrm{C}$ but did not grow at $45^{\circ} \mathrm{C}$. This strain grew well in the presence of $5 \%$ ethanol and weakly at $10 \%$ ethanol but did not grow at $15 \%$ ethanol. 
Table 2. Characteristics of Cocoa fermentation-related physiological

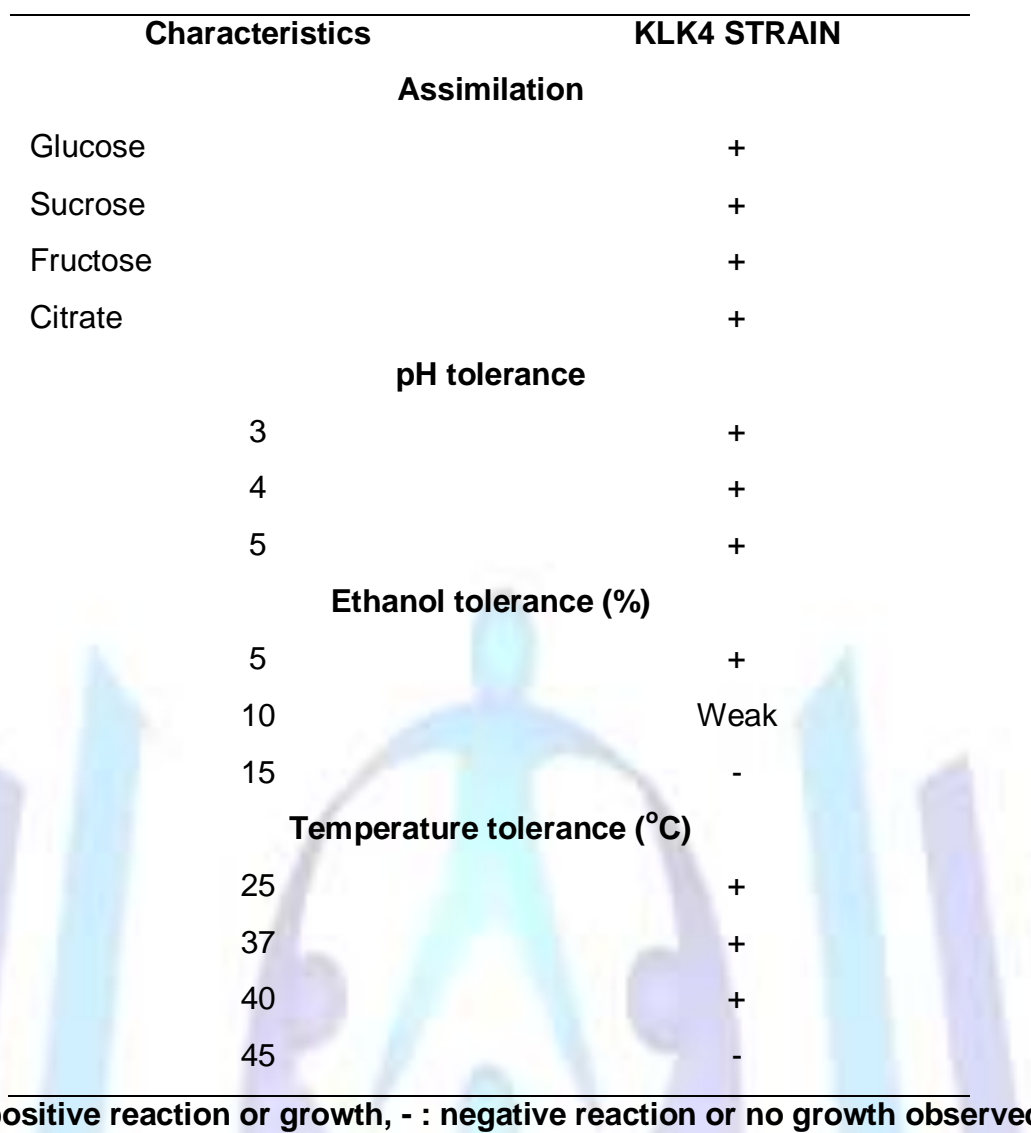

Based on physiological characteristics, it can be obtained several information to know adaptation ability of the yeast isolate to the cocoa bean fermentation environment. The KLK4 yeast strain was able to assimilate citrate and the tolerance of low $\mathrm{pH}$ value was in accordance with environmental conditions prevailing during cocoa bean fermentation, i.e. low $\mathrm{pH}$ at the start of the fermentation due to a high-citrate concentration.

\section{Quality of Fermented Cocoa Beans}

The role of KLK4 yeast strain on the improvement of cocoa quality was determined based on result of the cut test and fat content of the dry cocoa bean. The quality characteristics of cocoa bean after fermentation is shown in the Table 3 .

Table 3. Quality characteristics of fermented cocoa bean in $\mathbf{5}$ days fermentation.

\begin{tabular}{cccccccc}
\hline \multirow{2}{*}{$\begin{array}{c}\text { Experiment } \\
\text { regimens }\end{array}$} & $\begin{array}{c}\text { Fermentation } \\
\text { time (days) }\end{array}$ & $\begin{array}{c}\text { Slaty } \\
(\%)\end{array}$ & $\begin{array}{c}\text { Purple } \\
(\%)\end{array}$ & $\begin{array}{c}\text { Brown } \\
(\%)\end{array}$ & $\begin{array}{c}\text { Moldy } \\
(\%)\end{array}$ & $\begin{array}{c}\text { Germinated } \\
(\%)\end{array}$ & $\begin{array}{c}\text { Fat Content } \\
(\%)\end{array}$ \\
\hline Control & 0 & 93,33 & 6,67 & 0,00 & 0 & 0 & 42,18 \\
& 3 & 40,00 & 26,67 & 33,33 & 0 & 0 & 45,73 \\
\hline $\begin{array}{c}\text { Fermentation } \\
\text { with KLK4 }\end{array}$ & 5 & 10,00 & 33,33 & 56,67 & 0 & 0 & 45,77 \\
\hline strain addition & 3 & 90,00 & 10,00 & 0,00 & 0 & 0 & 44,63 \\
& 5 & 23,33 & 20,00 & 56,67 & 0 & 0 & 49,60 \\
\hline
\end{tabular}

\section{*Control (fermentation without inoculums addition/standard fermentation)}

The cut test result and fat content of cocoa bean revealed significant differences in the outcomes of the fermentations (Table 3). Generally, there were increases in brown beans with increasing fermentation time for both of the treatments. The brown beans (fermented beans) increased from $0 \%$ to $56,67 \%$ and from $0 \%$ to $83,33 \%$ while slaty beans (unfermented beans) decreased from $93 \%$ to $10 \%$ and $90 \%$ to $0 \%$ for the control (natural fermentation) and fermentation with KLK4 strain addition for 5 days, respectively, at the end of drying. There were also reductions in the purple beans with increasing fermentation time for both treatment. The percentage of purple beans at the end of fermentation for both 
treatment ranged from $16,67 \%$ to $33,33 \%$. Results showed that the proportion of purple beans did not exceed $50 \%$ for all treatments and this gave an indication that the beans were adequately fermented.

Physical analyses at Table 3 showed that the formation of moldy beans was not detected at control and seeding experiment with KLK4 yeast strain. There was not obtained germinating beans for both fermentation treatments (Table 3).

Table 3 also showed that the fat content in cocoa bean was increase during fermentation ( $0,3,5$ day) for both of treatments. However, fat content cocoa beans was fermented using KLK4 yeast strain was higher $(51,24 \%)$ than control $(45,77 \%)$ at the end fermentation.

\section{DISCUSSION}

In this study KLK4 yeast strain was characterized by morphological and physiological features and molecular approaches, using D1/D2 LSU sequence. The character of KLK4 strain morphologically, i.e. ellipsoidal cell shape, formed pseudomycelium and ascospores not detected was similar with character of genus Candida [12].. Furthermore, identification using physiological characteristics, was needed to identify this yeast strain at species level. The KLK4 strain did not produce chlamydospores, assimilated of glucose, sucrose, maltose and citrate but it was unable to assimilate lactose and nitrate. This strain was able to ferment sucrose and grew well at $39^{\circ} \mathrm{C}$. According to the morphological and physiological characteristics of KLK4 strain exhibited very similar with Candida tropicalis.

Phenotypic characters of Candida tropicalis was reported by Kirsop et al. [12] and listed in National Collection Yeast Cultures [16]. Description of Candida tropicalis, according to Kirsop et al. [2] and NCYC [16], i.e. the cells are ellipsoidal or ovoid to subspherical, single or in pairs or in small groups with multipolar budding and formed pseudomycelium. On PDA, the colonies are round, convex, smooth, and white to cream colored. Ascospores and chlamydospores are not detected. Assimilation of glucose, sucrose, maltose, D-galactose and cellobiose is positive but lactose, raffinose, Lrhamnosa, erythritol, innositol and nitrate is negative. This species unable to hydrolyze urea. Hence, the KLK4 strain was indicated as a member of Candida tropicalis based on phenotypic characterization. However, identification using the molecular characterization was needed for validation the result of phenotypically identification.

Most of the studies dealing with yeast identification are based on phenotypic characterization [3, 15], followed by molecular identification of the picked up isolates, often based on sequencing of the D1/D2 domain of the 26S rRNA gene $[11,7]$. In the yeasts, exclusively used for phylogenetic inferences are the variable domains at the 5 -end of the large subunit (26S) rDNA [14]. D1/D2 domain of 26S rDNA allows analysis to species level [7,14.].

From the result of the phylogenetic analysis using D1/D2 sequence (Figure 2) demonstrated that KLK4 yeast strain was closely related with $C$. tropicalis. This isolate revealed a high level similarity $(99,83 \%$ nucleotide identity) and differed only by $1 \mathrm{bp}$ for D1/D2 fragment from $C$. tropicalis XJURML (EF151501). Kurtzman \& Robnett [14] declared that normally strains of the same species have identical D1/D2 sequences or no more than $1 \%$ mismatch. Hence, this result clearly indicating that KLK4 strain belong to $C$. tropicalis. In this study, the genotypic identification showed that the congruence result with phenotypic identification. Therefore, The yeast strain KLK4 was a member of Candida tropicalis species.

The result of characteristics of cocoa fermentation-related physiological revealed that KLK4 strain plays an important role in the cocoa beans fermentation. The ability of KLK4 strain assimilated glucose, fructose and sucrose showed that this strain was able to degrade pulp to give ethanol. Ardhana \& Fleet [3] reported that the pulp cocoa bean are containing glucose, sucrose and fructose and yeasts were utilized during fermentation.

The tolerance of low $\mathrm{pH}$ value (3-5), ethanol concentration (5-10\%) and the high temperature $\left(40^{\circ} \mathrm{C}\right)$ of the $\mathrm{KLK} 4$ strain was in accordance with environmental conditions prevailing during cocoa beans fermentation. The higher temperatures, lowest $\mathrm{pH}$ value and ethanol concentrations towards the end of a cocoa bean fermentation, due to increased microbial activities, influence survival of cocoa-specific yeast species, as their tolerance towards these factors was variable [3,7,11]. The limited number of yeasts capable to grow at these conditions [3,7]. C. tropicalis gave significant growth at the higher temperature of $40^{\circ} \mathrm{C}$ and Candida species grew well in the presence of $7 \%$ ethanol and weakly at $10 \%$ ethanol [3]. The limited number of yeasts capable to grow at $45^{\circ} \mathrm{C}$ explains the disappearance of the yeast population once ethanol oxidation by acetic acid bacteria, causing a substantial temperature increase during cocoa bean fermentation, has started [6].

The presented results showed that addition of $C$. tropicalis KLK4 starter to the cocoa bean fermentation can improve the percentage of fermented beans and fat content during fermentation. The fermented cocoa bean was characterized by fully brown beans $[8,13]$. Changes in anthocyanins and oxidation products of the polyphenol oxidase might have contributed to the brown pigments formation in the cocoa beans during the fermentation period [2]. The decreasing of polyphenols and anthocyanins content normally lead to the changes of cocoa beans colour from purple to brown [2,6]. Buamah et al. [5] reported that fermentation cocoa with pure yeast (Saccharomyces chevalieri) addition could lead to beans of acceptable quality based on its ability reduce of anthocyanins content of the cocoa bean. The percentage of brown beans achieved $83 \%$ at the end fermentation indicated that the cocoa quality has been increase after was fermented by $C$. tropicalis KLK4. Afoakwa et al. [2] reported that cocoa flavours developed best when the degree of fermentation (\% fully brown beans) was above $60 \%$.

Addition of $C$. tropicalis KLK4 to cocoa bean fermentation also was able to increase fat content. The fat content of dry cocoa bean increased from $44,63 \%$ to $51,24 \%$ for cocoa beans was fermented by C. tropicalis KL4, at the end fermentation. Improvement of fat content of cocoa bean after fermentation indicated that C.tropicalis KLK4 is able to 
enhance quality of cocoa. The lipid composition in cocoa influences melting properties and mouthfeel character [1] hence, the fat content of cocoa bean determine cocoa quality.

These results suggest that an indigenous yeast Candida tropicalis KLK4 can be used as inoculums for cocoa bean fermentation to obtain the good cocoa quality.

\section{CONCLUSIONS}

Candida tropicalis KLK4 was an indigenous yeast from Southeast Sulawesi, Indonesia that play a role on cocoa bean fermentation process. The addition of $C$. tropicalis KLK4 into cocoa bean fermentation can enhance of cocoa quality, especially brown bean (fermented beans) and fat content. This species is essential to the fermentation and the development of cocoa bean and chocolate quality.

\section{AUTHOR'S CONTRIBUTIONS}

Jamili designed the protocol the research and contributed to draft the manuscript, NAY executed the laboratory work and drafted the manuscript and PES contributed to monitor the laboratory work and provided required chemicals and laboratory consumables for different analysis. All authors read and approved the manuscript.

\section{ACKNOWLEDGMENTS}

The research was supported a PEMPRINAS MP3EI research grant by Indonesian Directorate General of Higher Education, No. 255/SP2H/PL/DIT.LITABMAS/VII/2014, Ministry of Government of Indonesia, for which the authors are grateful.

\section{REFERENCES}

[1] Afoakwa, E. O. 2010. Chocolate Science and Technology. Wiley-Blackwell Publishers, Oxford, UK, pp $20-22$.

[2] Afoakwa, E.O., Quao, J., Takrama, J., Budu, A.S., Saalia, F.K., 2012.Changes in total polyphenols, o-diphenols and anthocyanin concentrations during fermentation of pulp pre-conditioned cocoa (Theobroma cacao) beans, Int. Food Res. J. 19 (3) : 1071-1077

[3] Ardhana MM \& Fleet G (2003) The microbial ecology of cocoa bean fermentations in Indonesia. Int J FoodMicrobiol 86: 87-99.

[4] AOAC. 2005. Official Method 963.15, Fat in Cocoa Product. Association of Official Analytical chemistry (AOAC).

[5] Buamah, R., Dzogbefia, D.P. and Oldham, J.H. 1997. Pure yeast culture fermentation of cocoa (Theobroma cacao L): effect on yield of sweatings and cocoa bean quality. World Journal of Microbiology \& Biotechnology 13, 457-462

[6] Camu, N., De Winter, T., Verbrugghe, K., Cleenwerck, I., Vandamme, P., Takrama, .JS., Vancanneyt, M. \& De Vuyst, L. 2007. Dynamics and biodiversity of populations of lactic acid bacteria and acetic acid bacteria involved in spontaneous heap fermentations of cocoa beans in Ghana. Appl. Environ. Micob. 73: 1809-1824.

[7] Daniel, H.M., Vrancken, G., Takrama, J. F., Camu, N., De Vos, P. \& De Vuyst, L. 2009. Yeast diversity of Ghanaian cocoa bean heap fermentations. FEMS Yeast Res $9:$ 774-783.

[8] Guehi, T.S., Koffi, K.P.B. and Dabonne, S. 2010. Spontaneous Cocoa Bean Heap Fermentation: Influence of the Duration and Turning on the Quality of Raw Cocoa. World Academy of Science, Engineering and Technology 46 : 112-123

[9] Hansen, G.E., Olmo, M.D. \& Burns, C. 1998. Enzyme activities in cocoa beans during fermentation. J. Sci. Food Agric. 77: 273-81

[10] Ho, V.T.T., Zhao, J. and Fleet, G. 2014. Yeasts are essential for cocoa bean fermentation. International Joumal of FoodMicrobiology $174: 72-87$.

[11] Jespersen, L., Nielsen, D.S., Hønholt, S. and Jakobsen, M. 2005. Occurrence and diversity of yeasts involved in fermentation of West African cocoa beans. FEMS Yeast Research 5: 441-453

[12] Kirsop, B., Painting, K. and Henry, J. 1984. Yeast : Their identification. Thailand Institute of Scientific and Technology Research, Bangkok. Pp :97-170

[13] Kongor, J.E.,,Takrama, J.F., Budu, A.S., Mensah-Brown, H. and Afoakwa, E.O. 2013. Effects of Fermentation and Drying on the Fermentation Index and Cut Test of Pulp Pre-conditioned Ghanaian Cocoa (Theobroma cacao) Beans. Journal of Food Science and Engineering 3 : 625-634

[14] Kurtzman, C.P. and Robnett, C. 1998.Identification and phylogeny of ascomycetous Yeasts; from analysis of nuclear large subunit (26S) ribosomal DNA partial Sequences, Ant Van Leeuwen. 73 : 331-371.

[15] Lagune-Gálvez, S., Loiseau, G., Paredes, J.L., Barel, M. and Guiraud, J.P. 2007. Study on the microflora and biochemistry of cocoa fermentation in the Dominican Republic. International Journal of Food Microbiology 114 : 124-130

[16] National Collection Yeast Cultures Internet source. http://www.ncyc.co.uk.

[17] Saitou, N. \& Nei, M. 1987. The Neighbour-joining Method : A New Method for Reconstructing Phylogenetic Trees, Molecular Biology \& Evolution 4 : 406-426 


\section{ISSN 2348-6201}

[18] Sanchez, J., Daguenet, G., Guiraud, P.J., Vincent, J.C. \& Galzy, P. 1985 A study of the yeast flora and the effect of pure culture seeding during the fermentation process of cocoa beans. Lebensmiddelen Wissenschaft und Technologie 18, 69-75.

[19] Schwan, R.F. \& Wheals, A.E. 2004. The Microbiology of Cocoa Fermentation and its Role in Chocolate Quality. Critical Reviews in Food Science and Nutrition 44 (4) : 205-221.

[20] Wood, G.A.R and Lass, R.A. 1985. International Cocoa Satndards. In Cocoa 4th Edition, Longman Group Ltd.

\section{Author' biography with Photo}

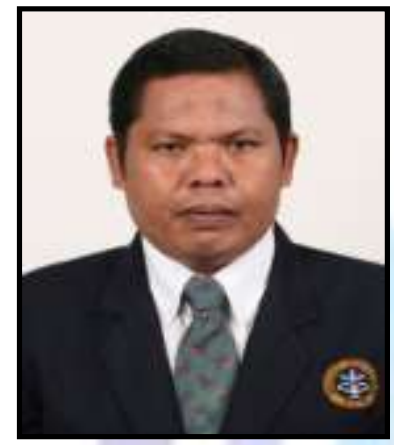

Dr. Jamili completed his Ph.D in Biology from Bogor Agricultural University in Bogor, Indonesia. $\mathrm{He}$ is the head of Biology Department of the Faculty of Mathematics and Natural Science Halu Oleo University, Kendari Southeast Sulawesi, Indonesia. His current research interests are on the topics of fermentation, mangrove ecology and tropical biodiversity 